\title{
Phylogenetic insights on the isoflavone profile variations in Fabaceae spp.: Assessment through PCA and LDA
}

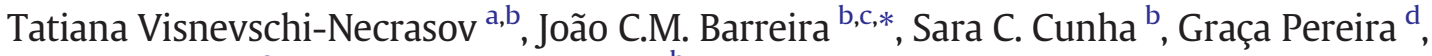 \\ Eugénia Nunes ${ }^{\mathrm{a}}$, M. Beatriz P.P. Oliveira ${ }^{\mathrm{b}}$ \\ a CIBIO-ICETA, Faculdade de Ciências, Universidade do Porto, R. Padre Armando Quintas 4485-661 Vairão, Portugal \\ b REQUIMTE, Departamento de Ciências Químicas, Faculdade de Farmácia, Universidade do Porto, Rua Jorge Viterbo Ferreira, No. 228, 4050-313, Porto,Portugal \\ c CIMO-ESA, Instituto Politécnico de Bragança, Campus de Santa Apolónia, Apartado 1172, 5301-855 Bragança, Portugal \\ d INRB/IP - INIA - Instituto Nacional de Recursos Biológicos, Caia E São Pedro Estrada Gil Vaz, 7350-228 Elvas, Portugal
}

\section{A R T I C L E I N F O}

\section{Article history:}

Received 30 September 2014

Received in revised form 15 November 2014

Accepted 20 November 2014

Available online 28 November 2014

\section{Chemical compounds studied in this article:}

Daidzin (PubChem CID: 107971)

Genistin (PubChem CID: 5281377)

Daidzein (PubChem CID: 5281708)

Glycitein (PubChem CID: 5317750)

Genistein (PubChem CID: 5280961)

Pratensein (PubChem CID: 5281803)

Formononetin (PubChem CID: 5280378)

Irilone (PubChem CID: 5281779)

Prunetin (PubChem CID: 5281804)

Biochanin A (PubChem CID: 5280373 )

Keywords:

Isoflavone profile

Genotypic effects

Fabaceae

PCA

LDA

\begin{abstract}
A B S T R A C T
Legumes (Fabaceae) are important crops, known as sources of food, feed for livestock and raw materials for industry. Their ability to capture atmospheric nitrogen during symbiotic processes with soil bacteria reduces the need for expensive chemical fertilizers, improving soil and water quality. Several Fabaceae species are acknowledged for the high levels of secondary metabolites. Isoflavones are among the most well-known examples of these compounds, being recognized for their several types of biological activity. Herein, isoflavone profiles were characterized in nine species of four Fabaceae genera (Biserrula, Lotus, Ornithopus and Scorpiurus). Plants were harvested in the late flower physiological stage to prevent biased results due to naturally occurring variations along the vegetative cycle. Isoflavones were extracted using matrix solid-phase dispersion and analyzed by high performance liquid chromatography/diode-array detection. The detected profiles revealed significant differences, inclusively among species belonging to the same genus, indicating that other factors besides the genotypic features contribute to the expression of these phenolic compounds. The classification of the results by principal component analysis placed species belonging to the same genus in different clustering groups, proving this latter assumption. However, the detected profiles proved to be characteristic of the assayed, as it was proved by the applied linear discriminant analysis.
\end{abstract}

C 2014 Elsevier Ltd. All rights reserved.

\section{Introduction}

Species belonging to Fabaceae family, commonly known as legumes, have been essential to the development of modern agriculture (Boerma, John \& Molen, 2001). In fact, legumes are the second most important crop as source of food, feed for livestock and raw materials for industry (Udvardi et al., 2007). In symbiosis with soil bacteria, legumes capture nearly 17 million metric tons of atmospheric nitrogen, reducing the use of expensive chemical fertilizers and the need for petroleum derivatives (Boerma et al., 2001).

\footnotetext{
* Corresponding author at: REQUIMTE, Departamento de Ciências Químicas, Faculdade de Farmácia, Universidade do Porto, Rua Jorge Viterbo Ferreira, No. 228, 4050-313, Porto, Portugal. Tel.: + 351273 303909; fax: + 351273325405

E-mail address: jbarreira@ipb.pt (J.C.M. Barreira).
}

The Fabaceae species selected for this study (Table 1) are native from the Mediterranean areas of Europe, Africa and Canary Islands, being characterized for their deep radical system, good quality of hay and silage and compatibility with summer-growing perennial grasses. These nutritious and palatable species tolerate high levels of soil-available aluminum and low $\mathrm{pH}$, growing preferably in deep, sandy and acid soils, besides being suited for self-regenerating annual pasture (Hackney, Dear \& Crocker, 2007). Species belonging to Lotus and Ornithopus genera are found in Macaronesian Islands (Azores, Madeira, Canary Islands and Cape Verde); some Lotus species might also be found in the North, Central and/or South America (Santos, 2007). Besides the Canary Islands, species belonging to Scorpiurus genus are found on the southern region of Portugal and Spain (Scorpiurus muricatus and Scorpiurus vermiculatus), Sardinia, Malta (S. muricatus) and other Mediterranean regions (Zielinski, 1991). Biserrula pelecinus is important in Australia, where the first commercially available cultivars (Casbah and Mauro) were produced (Hackney et al., 2007). 
Table 1

Evaluated species of Fabaceae plants grown in the Agrarian Station of Vairão at the experimental field of University of Porto, Portugal.

\begin{tabular}{lc}
\hline Species & Accessions \\
\hline Biserrula pelecinus L. & 1 \\
& 5 \\
Lotus conimbricensis Brot. & 23 \\
& 24 \\
Lotus subbiflorus Lag. & 29 \\
Ornithopus compressus L. & 30 \\
& 129 \\
Ornithopus pinnatus (Mill.) Druce & 148 \\
& 167 \\
Ornithopus sativus Brot. & 170 \\
& 175 \\
Scorpiurus muricatus L. & 176 \\
Scorpiurus vermiculata L. & 199 \\
& 202 \\
Scorpiurus vermiculatus L. & 212 \\
& 213 \\
\end{tabular}

The importance of legumes is also associated with their secondary metabolites, particularly phytoestrogens (Yildiz, 2005). The three main classes of phytoestrogens are isoflavones, lignans and coumestans (Jacobs, Wegewitz, Sommerfeld, Grossklaus \& Lampen, 2009), and their biosynthesis depends highly on the environment and plant species (Martin, Castilho, Silveira \& Abreu, 2006). Several plant phenolic compounds are known to be antimicrobial or signaling molecules, acting frequently as phytoanticipins, phytoalexins, structural barriers, modulators of pathogenicity, or plant defense gene activators (Hammerschmidt, 2005). Isoflavones, in particular, have an important role during the interaction of Fabaceae species with nitrogen-fixing bacteria (Phillips \& Kapulnik, 1995), modulating the soil microbial communities, with particular importance in interactions between roots and microorganisms (Cooper, 2007; Guo, Kong, Wang \& Wang, 2011). Concerning their effect on human health, isoflavones are known for their ability to decrease the morbidity rates due to age-related cardiovascular diseases and osteoporosis, hormone-dependent breast and prostate cancers (mainly attributed to the structural resemblance between isoflavones and estradiol), and menopausal symptoms (Cano, García-Pérez \& Tarín, 2010; Mourouti \& Panagiotakos, 2013; Park \& Weaver, 2012).

Isoflavones are typically associated with soybean, despite being commonly synthesized by other Fabaceae plants, such as alfalfa, clover, pea, peanut, beans, (Jacobs et al., 2009) or Medicago spp. (VisnevschiNecrasov et al., 2014).

Matrix solid-phase dispersion (MSPD) technique has been successfully applied in the extraction of isoflavones. Their analysis is usually based on high-performance liquid chromatography (HPLC) coupled with different detectors (Aguiar, Baptista, Alencar, Haddad \& Eberlin, 2007; Fiechter, Opacak, Raba \& Mayer, 2013; Visnevschi-Necrasov et al., 2014; Visnevschi-Necrasov, Cunha, Nunes \& Oliveira, 2009).

Herein, the free and conjugated isoflavone profiles of selected openfield Fabaceae species harvested in the late flower physiological stage were determined and evaluated through principal component analysis to understand how these phytoestrogens vary in response to phylogenetic effects, acting as a potential indicator of the adaptation level of these legumes to their ecological environment. Extractions and chromatographic methodologies were applied as previously optimized (Visnevschi-Necrasov et al., 2014).

\section{Materials and methods}

\subsection{Standards and reagents}

Acetonitrile (HPLC grade) and formic acid (analytical grade) were from Merck (Darmstadt, Germany). Purified demineralized water used was from a "Seradest LFM 20" system (Seral, Ransbach-Baumbach, Germany). The eluents were filtered through $0.45 \mu \mathrm{m}$ filters and degassed under reduced pressure and ultrasonic bath. Disposable syringe filter PTFE $0.45 \mu \mathrm{m}$ was from Macherey-Nagel (Düren, Germany). The $\mathrm{C}_{18}$-bonded silica (particle size $55-105 \mu \mathrm{m}$ ) used as sorbent for MSPD was from Waters (Milford, MA, USA).

\subsection{Plant material and field experimental site}

Nine species (Table 1) of four Fabaceae genera (Biserrula, Lotus, Ornithopus and Scorpiurus) were cultivated from February to June of 2010, in the experimental field of the University of Porto at the Agrarian Station of Vairão, in Portugal. No chemical fertilizers were used and plants were not inoculated with nitrogen-fixing bacteria. Plants were harvested in the late flower physiological stage (one or more nodes with $50 \%$ open flowers, no seed pods). The vegetal germplasm was obtained from the Portuguese collection of Leguminosae provided by the National Institute of Biological Resources (Instituto Nacional dos Recursos Biológicos, I.P.). Voucher specimens of each species were numbered and deposited in the local herbarium.

For each species, three independent samples were selected (in different locations within the limits of the indicated experimental field) consisting of fresh leaves from randomly selected plants ( 5 plants for each accession) belonging to 2 different accessions; samples were dried at $65^{\circ} \mathrm{C}$ for $72 \mathrm{~h}$ and milled, at particle size of $0.1 \mathrm{~mm}$, using an A11 analysis mill (IKA Werke, Staufen, Germany). Samples were stored in silicone tubes at room temperature.

\subsection{Extraction procedure}

MSPD extraction of isoflavones was applied with small modifications of a previous method (Visnevschi-Necrasov et al., 2014). An aliquot of $500 \mathrm{mg}$ of the previously milled dried sample, $2 \mathrm{~g}$ of $\mathrm{C}_{18}$ and $40 \mathrm{mg} / \mathrm{kg}$ of 2-methoxyflavone ( $200 \mu \mathrm{L}$ at $100 \mathrm{mg} / \mathrm{L})$, used as internal standard, were placed in a glass mortar and blended with glass pestle for 2-3 min. This mixture was then transferred to an empty column connected to a vacuum system. The column was washed with $10 \mathrm{~mL}$ of distilled water (reddish-brown phase eluted from the column) and the isoflavones were eluted with $5 \mathrm{~mL}$ of methanol: $\mathrm{H}_{2} \mathrm{O}(9: 1, \mathrm{v} / \mathrm{v})$. Before HPLC analysis, the extracts collected in amber vials were filtered through a $0.45 \mu \mathrm{m}$ PTFE membrane. Different samples of two distinct accessions of all species were extracted.

\subsection{HPLC determination of isoflavones}

Purity-corrected individual isoflavones stock solutions ( $1 \mathrm{~g} / \mathrm{L})$ were prepared in methanol: $\mathrm{H}_{2} \mathrm{O}(75: 25, \mathrm{v} / \mathrm{v})$. A composite stock standard solution of multiple isoflavones containing $40 \mathrm{mg} / \mathrm{L}$ of each standard: biochanin $A(\geq 97 \%)$, puerarin ( $\geq 99 \%)$, glycitein ( $\geq 97 \%)$, daidzein ( $\geq 98 \%$ ), daidzin ( $\geq 95 \%)$, prunetin $(\geq 98 \%)$, genistein $(\geq 98 \%)$, genistin $(\geq 95 \%)$ and formononetin $(\geq 99 \%$ ) (Sigma-Aldrich, St. Louis, MO, USA); pratensein and irilone (both $\geq 98 \%$ ) (Chromadex Inc., Barcelona, Spain) was prepared. The internal standard (IS) 2-methoxyflavone was obtained from Sigma. A working 2-methoxyflavone solution was prepared in methanol at $1 \mathrm{~g} / \mathrm{L}$. All the solutions were stored at $-20{ }^{\circ} \mathrm{C}$ in amber glass vials when not in use.

Chromatographic analyses were performed with a Jasco (Tokyo, Japan) high-performance liquid chromatograph equipped with a PU2080 quaternary pump and a Jasco AS-950 automatic sampler with a $20 \mu \mathrm{L}$ loop. Detection was performed with a Jasco model MD-2010 multi-wavelength diode-array detector (DAD). Chromatographic separation of the compounds was achieved with a Luna $5 \mathrm{U} \mathrm{C}_{18}$ column ( $5 \mu \mathrm{m}, 150 \times 4.60 \mathrm{~mm}$; Teknokroma, Barcelona, Spain) operating at 40 ${ }^{\circ} \mathrm{C}$. The eluent was a gradient of acetonitrile $(\mathrm{A})$ and $0.1 \%$ formic acid (B), at a flow rate of $1 \mathrm{~mL} / \mathrm{min}$, with a linear gradient as follows: 0 min 33\% B, 7 min 45\% B, 15 min 50\% B, 25 min 60\% B, 30 min 70\% B, $35 \min 50 \%$ B, 37 min 33\% B, maintaining these conditions for 10 min 


\begin{tabular}{|c|c|c|c|c|c|c|}
\hline Isoflavones & $\mathrm{R}_{1}$ & $\mathrm{R}_{2}$ & $\mathrm{R}_{3}$ & $\mathrm{R}_{4}$ & $\mathrm{R}_{5}$ & $\mathrm{R}_{6}$ \\
\hline Daidzin & $\mathrm{H}$ & $\mathrm{H}$ & $O$-Glucose & $\mathrm{H}$ & $\mathrm{H}$ & $\mathrm{OH}$ \\
\hline Genistin & $\mathrm{OH}$ & $\mathrm{H}$ & $O$-Glucose & $\mathrm{H}$ & $\mathrm{H}$ & $\mathrm{OH}$ \\
\hline Daidzein & $\mathrm{H}$ & $\mathrm{H}$ & $\mathrm{H}$ & $\mathrm{H}$ & $\mathrm{H}$ & $\mathrm{OH}$ \\
\hline Glycitein & $\mathrm{H}$ & $\mathrm{OCH}_{3}$ & $\mathrm{H}$ & $\mathrm{H}$ & $\mathrm{OH}$ & $\mathrm{OH}$ \\
\hline Genistein & $\mathrm{OH}$ & $\mathrm{H}$ & $\mathrm{H}$ & $\mathrm{H}$ & $\mathrm{H}$ & $\mathrm{OH}$ \\
\hline Pratensein & $\mathrm{OH}$ & $\mathrm{H}$ & $\mathrm{H}$ & $\mathrm{H}$ & $\mathrm{OH}$ & $\mathrm{OCH}_{3}$ \\
\hline Formononetin & $\mathrm{H}$ & $\mathrm{H}$ & $\mathrm{H}$ & $\mathrm{H}$ & $\mathrm{H}$ & $\mathrm{OCH}_{3}$ \\
\hline Irilone & $\mathrm{OH}$ & $\mathrm{O}-$ & $-\mathrm{CH}_{2-}$ & $\mathrm{H}$ & $\mathrm{H}$ & $\mathrm{OH}$ \\
\hline Prunetin & $\mathrm{OH}$ & $\mathrm{H}$ & $\mathrm{CH}_{3}$ & $\mathrm{H}$ & $\mathrm{H}$ & $\mathrm{OH}$ \\
\hline Biochanin A & $\mathrm{OH}$ & $\mathrm{H}$ & $\mathrm{H}$ & $\mathrm{H}$ & $\mathrm{H}$ & $\mathrm{OCH}_{3}$ \\
\hline
\end{tabular}

Scheme 1. Structures of the isoflavones identified in different species from Biserrula, Lotus, Ornithopus and Scorpiurus genera.

and returning to the initial ones after 3 min. Data were analyzed using the Borwin-PDA Controller Software (JMBS, Le Fontanil, France). Compounds were identified by chromatographic comparisons with authentic standards and UV spectra. Quantification was made by DAD at $254 \mathrm{~nm}$ based on the internal standard (2-methoxyflavone) method.

\subsection{Statistical analysis}

All extractions were performed in triplicate and each replicate was quantified in duplicate. Data were expressed as means \pm standard deviations. All statistical tests were performed at a 5\% significance level using the SPSS software, version 22.0 (SPSS Inc).

The statistical differences represented by letters were obtained through one-way analysis of variance (ANOVA). The fulfillment of the one-way ANOVA requirements, specifically the normal distribution of the residuals and the homogeneity of variance, was tested by means of the Kolmogorov-Smirnov with Lilliefors correction and the Levene's tests, respectively. In the cases where statistical significance differences were identified, the dependent variables were compared using Tukey's honestly significant difference (in homoscedastic samples) or Tamhane's T2 (in heteroscedastic samples).

Principal components analysis (PCA) was applied as pattern recognition unsupervised classification method. PCA transforms the original, measured variables into new uncorrelated variables called principal components. The first principal component covers as much of the variation in the data as possible. The second principal component is orthogonal to the first and covers as much of the remaining variation as possible, and so on (Patras et al., 2011). The number of dimensions kept for data analysis was evaluated by the respective eigenvalues (which should be higher than one), by the Cronbach's alpha parameter (that must be positive) and also by the total percentage of variance (that should be as high as possible) explained by the number of selected components. The number of plotted dimensions was chosen in order to allow meaningful interpretations, and by ensuring their reliability.

In addition, a linear discriminant analysis (LDA) was used to evaluate the association of the genus and the isoflavone profile. A stepwise technique, using the Wilks' $\lambda$ method with the usual probabilities of $F$ (3.84 to enter and 2.71 to remove), was applied for variable selection. This procedure uses a combination of forward selection and backward elimination procedures, where before selecting a new variable to be included, it is verified whether all variables previously selected remain significant (Palacios-Morillo, Alcázar, Pablos \& Jurado, 2013). With this approach, it is also possible to identify the significant variables that contribute in higher extent to the discrimination of a determined genus. To verify which canonical discriminant functions were significant, the Wilks' $\lambda$ test was applied. A leaving-one-out cross-validation procedure was carried out to assess the model performance.

\section{Results and discussion}

This study quantified ten isoflavones with the following elution order: daidzin (daidzein-7-0-glucoside), genistin (genistein-7-0-glucoside), daidzein (4',7-dihydroxyisoflavone), glycitein (4',7-dihydroxy-6-methoxyisoflavone), genistein (4',5,7-trihydroxyisoflavone), pratensein (4'-methoxy-3',5,7-trihydroxyisoflavone), formononetin (7-hydroxy-4'-methoxyisoflavone), irilone (9-hydroxy-7-(4-hydroxyphenyl)-[1,3]dioxolo [4,5-g]chromen-8-one), prunetin (4',5-dihydroxy-7-methoxyisoflavone) and biochanin A (5,7-dihydroxy-4'methoxyisoflavone) (Scheme 1).An exemplifying chromatogram, corresponding to Lotus subbiflorus in the late bud (LB) stage, is presented in Fig. 1. Isoflavone profiles varied greatly among the assayed Fabaceae species (Table 2). Lotus conimbricensis presented the highest content in isoflavones ( $3360 \pm 92 \mathrm{mg} / \mathrm{kg} \mathrm{DM}$ ), mostly due to its biochanin A quantity (3092 $\pm 91 \mathrm{mg} / \mathrm{kg} \mathrm{DM}$ ); on the other hand, $S$. muricatus presented the lowest overall content ( $65 \pm 1 \mathrm{mg} / \mathrm{kg} \mathrm{DM})$. The biochanin A levels 


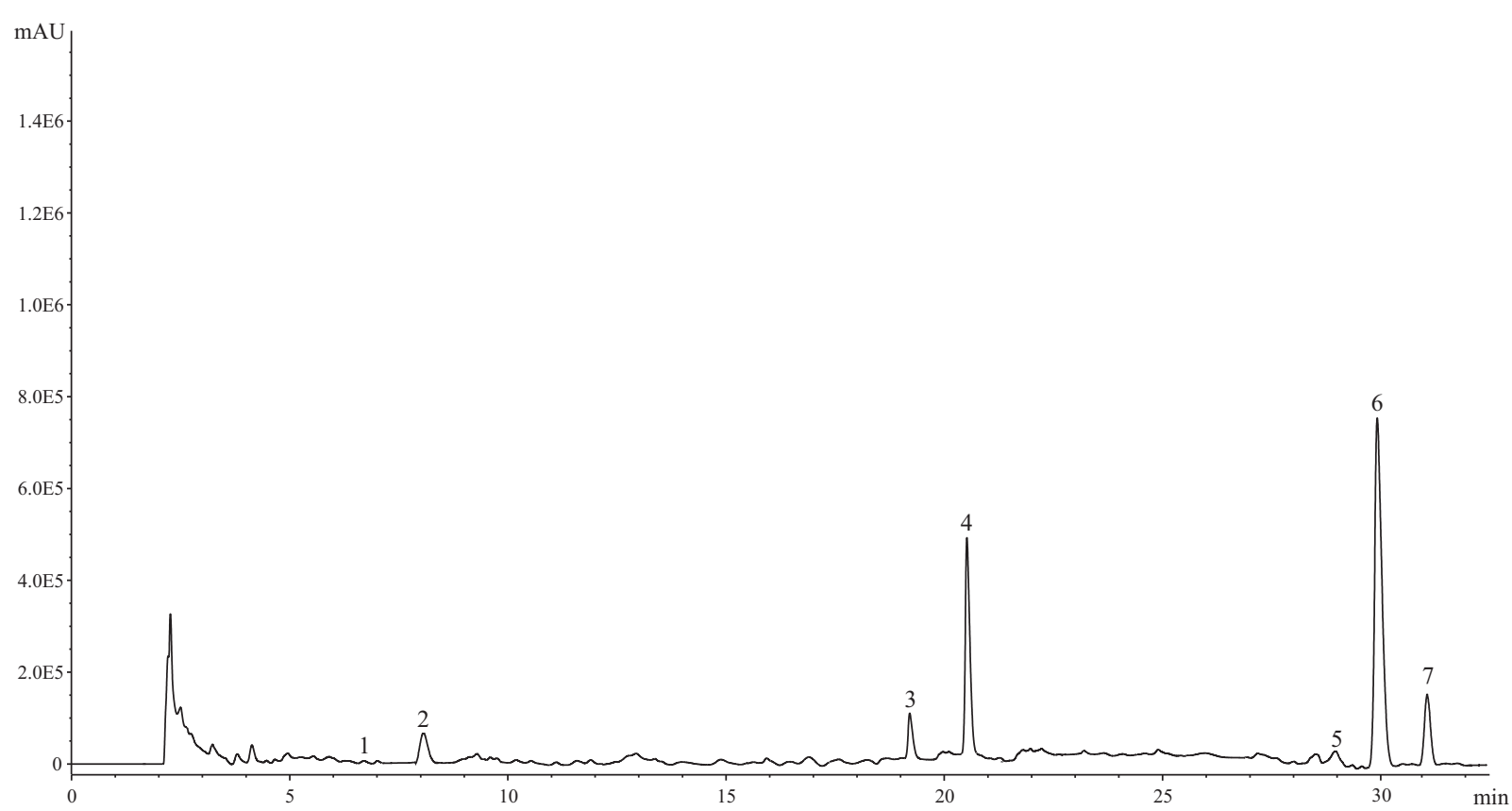

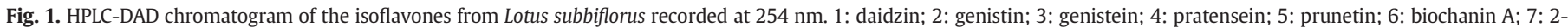
methoxyflavone (IS).

in B. pelecinus and L. conimbricensis are noteworthy in view of important biological activity of this isoflavone (Saviranta et al., 2011). In what concerns total isoflavone, the quantified amounts were also higher than those presented by other vegetable samples like green bean, carrot, white cabbage, cauliflower, iceberg lettuce or artichoke (Konar, Poyrazoğlu, Köksal \& Artik, 2012).

Despite their phylogenetic relationship, these species showed also great qualitative differences. As it can be depicted from Table 2, B. pelecinus and Ornithopus pinnatus presented the highest content in daidzein ( $22 \pm 1 \mathrm{mg} / \mathrm{kg} \mathrm{DM}$, in both cases); genistein (98 $\pm 1 \mathrm{mg} / \mathrm{kg}$ $\mathrm{DM})$ and biochanin $\mathrm{A}(3092 \pm 92 \mathrm{mg} / \mathrm{kg} \mathrm{DM})$ were reached maximal values in L. conimbricensis; Lotus subbiflorus, on its side, presented the maximal contents in pratensein (217 $\pm 5 \mathrm{mg} / \mathrm{kg}$ DM) and prunetin (34 $\pm 1 \mathrm{mg} / \mathrm{kg} \mathrm{DM})$; the highest level of daidzin (73 $\pm 5 \mathrm{mg} / \mathrm{kg} \mathrm{DM})$ was quantified in Ornithopus compressus, while the top value for genistin (206 $\pm 8 \mathrm{mg} / \mathrm{kg} \mathrm{DM}$ ) was verified in O. pinnatus; finally, the highest content in glycitein ( $59 \pm 1 \mathrm{mg} / \mathrm{kg} \mathrm{DM}$ ) was given by Scorpiurus vermiculata, while formononentin $(53 \pm 1 \mathrm{mg} / \mathrm{kg} \mathrm{DM})$ and irilone
$(81 \pm 3 \mathrm{mg} / \mathrm{kg} \mathrm{DM})$ presented the maximal values in Scorpiurus vermiculatus.

Formononetin is a methylated form of daidzein, which is also the aglycone of daidzin; considering these isoflavones together, their different proportions among species seem to indicate differences in metabolic dynamics that cannot be explained by plant maturation, since all samples were harvested in the same phenological stage. The same reasoning could be applied to genistein, which might result from the demethylation of biochanin A or prunetin, as well as from the loss of a glucose moiety by genistin. In terms of biological activity, the efficiency of anaerobic demethylation by acetogenic bacteria is relatively low, but specific human hepatic enzymes are also capable of demethylating the proestrogenic isoflavones biochanin A, prunetin and formononetin to yield their demethylated derivatives with higher estrogenic activity. Plant isoflavones are usually found as substituted glucoside conjugates; thereby, their bioavailability and bioactivity require hydrolysis of glycosidic bonds to release the free aglycons (Tolleson, Doerge, Churchwell, Marques \& Roberts, 2002). Herein, most plants presented higher

Table 2

Isoflavones contents ( $\mathrm{mg} / \mathrm{kg}$ dry matter) in the evaluated Fabaceae species. The results are presented as mean $\pm \mathrm{SD}^{1}$.

\begin{tabular}{|c|c|c|c|c|c|c|c|c|c|c|c|}
\hline Species & Daidzin & Genistin & Daidzein & Glycitein & Genistein & Pratensein & Formononetin & Irilone & Prunetin & Biochanin A & Total \\
\hline Biserrula pelecinus $\mathrm{L}$. & nd & $33 \pm 1 c$ & $22 \pm 1 \mathrm{a}$ & $6.6 \pm 0.4 \mathrm{f}$ & $65 \pm 2 b$ & $17 \pm 1 \mathrm{f}$ & $37 \pm 2 b$ & $10 \pm 1 \mathrm{e}$ & nd & $2046 \pm 91 b$ & $2236 \pm 91 b$ \\
\hline Lotus conimbricensis Brot. & nd & $11.2 \pm 0.3 \mathrm{fg}$ & $10.1 \pm 0.3 \mathrm{e}$ & $12.3 \pm 0.5 \mathrm{~d}$ & $98 \pm 1 \mathrm{a}$ & $119 \pm 3 b$ & nd & $18 \pm 1 \mathrm{c}$ & nd & $3092 \pm 91 \mathrm{a}$ & $3360 \pm 92 a$ \\
\hline Lotus subbiflorus Lag. & $6 \pm 1 c$ & $56 \pm 1 b$ & nd & nd & $34 \pm 1 c$ & $217 \pm 5 a$ & nd & nd & $34 \pm 1 \mathrm{a}$ & $558 \pm 32 c$ & $906 \pm 32 c$ \\
\hline Ornithopus compressus L. & $73 \pm 5 a$ & $10.4 \pm 0.5 \mathrm{~g}$ & $4.2 \pm 0.2 \mathrm{f}$ & nd & $7.9 \pm 0.4 \mathrm{~h}$ & $16.3 \pm 0.3 \mathrm{fg}$ & $7.4 \pm 0.4 \mathrm{~d}$ & $6.5 \pm 0.3 \mathrm{f}$ & $10.0 \pm 0.4 c$ & $74 \pm 2 d$ & $210 \pm 5 \mathrm{e}$ \\
\hline $\begin{array}{l}\text { Ornithopus pinnatus } \\
\text { (Mill.) Druce }\end{array}$ & $18 \pm 1 b$ & $206 \pm 8 a$ & $22 \pm 1 \mathrm{a}$ & $33 \pm 1 c$ & $10.3 \pm 0.5 \mathrm{f}$ & $15 \pm 1 \mathrm{~g}$ & nd & $5.0 \pm 0.2 \mathrm{~g}$ & nd & nd & $309 \pm 3 d$ \\
\hline Ornithopus sativus Brot. & nd & $3.4 \pm 0.4 \mathrm{~h}$ & $3.4 \pm 0.3 \mathrm{~g}$ & nd & $13.3 \pm 0.4 \mathrm{e}$ & $28 \pm 2 \mathrm{e}$ & $18.7 \pm 0.4 \mathrm{c}$ & $15 \pm 1 \mathrm{~d}$ & $31 \pm 1 b$ & $7.6 \pm 0.4 \mathrm{e}$ & $120 \pm 3 \mathrm{f}$ \\
\hline Scorpiurus muricatus L. & nd & $19.3 \pm 0.4 \mathrm{e}$ & $13.3 \pm 0.4 c$ & $9.0 \pm 0.4 \mathrm{e}$ & $9.3 \pm 0.3 \mathrm{~g}$ & $3.1 \pm 0.2 \mathrm{~h}$ & nd & $1.7 \pm 0.1 \mathrm{~h}$ & nd & $9.5 \pm 0.5 \mathrm{e}$ & $65 \pm 1 \mathrm{f}$ \\
\hline Scorpiurus vermiculata $\mathrm{L}$. & nd & $12 \pm 1 \mathrm{f}$ & $16 \pm 1 \mathrm{~b}$ & $59 \pm 1 \mathrm{a}$ & nd & $73 \pm 1 c$ & nd & $26 \pm 1 \mathrm{~b}$ & nd & nd & $186 \pm 2 \mathrm{e}$ \\
\hline Scorpiurus vermiculatus L. & & $30 \pm 1 \mathrm{~d}$ & $11.4 \pm 0.5 \mathrm{~d}$ & $51 \pm 1 b$ & $18 \pm 1 \mathrm{~d}$ & $35 \pm 1 d$ & $53 \pm 1 \mathrm{a}$ & $81 \pm 3 a$ & & $8 \pm 1 \mathrm{e}$ & $288 \pm 3 d$ \\
\hline $\begin{array}{l}\text { Homoscedasticity } \\
\text { ( } p \text {-value })\end{array}$ & $<0.001$ & 0.021 & 0.009 & 0.001 & $<0.001$ & $<0.001$ & $<0.001$ & $<0.001$ & $<0.001$ & $<0.001$ & $<0.001$ \\
\hline $\begin{array}{l}\text { One-way ANOVA }{ }^{3} \\
(p \text {-value })\end{array}$ & $<0.001$ & $<0.001$ & $<0.001$ & $<0.001$ & $<0.001$ & $<0.001$ & $<0.001$ & $<0.001$ & $<0.001$ & $<0.001$ & $<0.001$ \\
\hline
\end{tabular}

1 Means within a column with different letters differ significantly ( $p<0.05$ ), evaluated using the multiple comparison Tamhane's T2 test, since none of the samples fulfilled the homoscedasticity requirement.

2 Homoscedasticity among cultivars was tested by means of the Levene test: homoscedasticity, $p$-value $>0.05$; heteroscedasticity, $p$-value $<0.05$.

${ }^{3} p<0.05$ meaning that the mean value of the evaluated parameter of at least one cultivar differs from the others (in this case multiple comparison tests were performed). 
contents of the aglycones in comparison to their glucoside conjugates, probably due to the late flower phenological stage in which samples were collected. This finding is highly relevant to predict the bioavailability of isoflavones, as well as their potential biological effects, which include a wide range of activities in human and farm animal organisms (Mortensen et al., 2009). Accordingly, by enhancing the knowledge regarding the profile of isoflavones in a determined plant, it is possible to select animal feeding in a more effective manner, by selecting the best species according to its specific use. This is surely a more natural approach than the metabolic engineering of isoflavonoid biosynthesis in legume and non-legume crops to provide dietary isoflavones (Yu \& McGonigle, 2005). Furthermore, isoflavones might act as phytoanticipins, phytoalexins, pathogenicity modulators, activators of plant defense genes, or signaling molecules in symbiotic processes (Cooper, 2007; Guo et al., 2011; Hammerschmidt, 2005; Phillips \& Kapulnik, 1995). Therefore, the different isoflavone levels detected in each plant species might be interpreted as an indicator of their adaptation to the edaphoclimatic conditions, since isoflavone accumulation and composition are affected by genotype and environmental conditions (Barion, Hewidy, Mosca \& Vamerali, 2010). B. pelecinus, in particular, is adapted to a broad range of soil types, particularly to well-drained ones (Revell \& Revell, 2007), while 0. pinnatus has better tolerance to waterlogged conditions, in contrast to 0 . compressus that is not well adapted to prolonged waterlogging (Doole, Pannell \& Revell, 2009). On the other hand, these species are not, in general, suited to clay or clay loam soils; their annual vegetative cycles require companion summer-growing species for all-year-round paddock production and good soil fertility and they are susceptible to pests such as lucerne flea and heliothis (Hackney et al., 2007; Revell \& Revell, 2007). The different profiles might also be explained by signals released by rhizobia, which have the ability to change the pattern of isoflavone accumulation in legumes roots and leaves (Khaosaad et al., 2008).

To obtain a comprehensive knowledge regarding the detected differences in isoflavone profiles, a principal component analysis (PCA) was applied. The plot of component loadings (Fig. 2) indicates that the first two dimensions included most of the variance of all quantified variables (35.4\% and 29.9\%, respectively). According to their Cronbach's alpha values (first dimension: 0.746; second dimension: 0.665; third dimension: 0.505; fourth dimension: 0.081) and eigenvalues (first dimension:

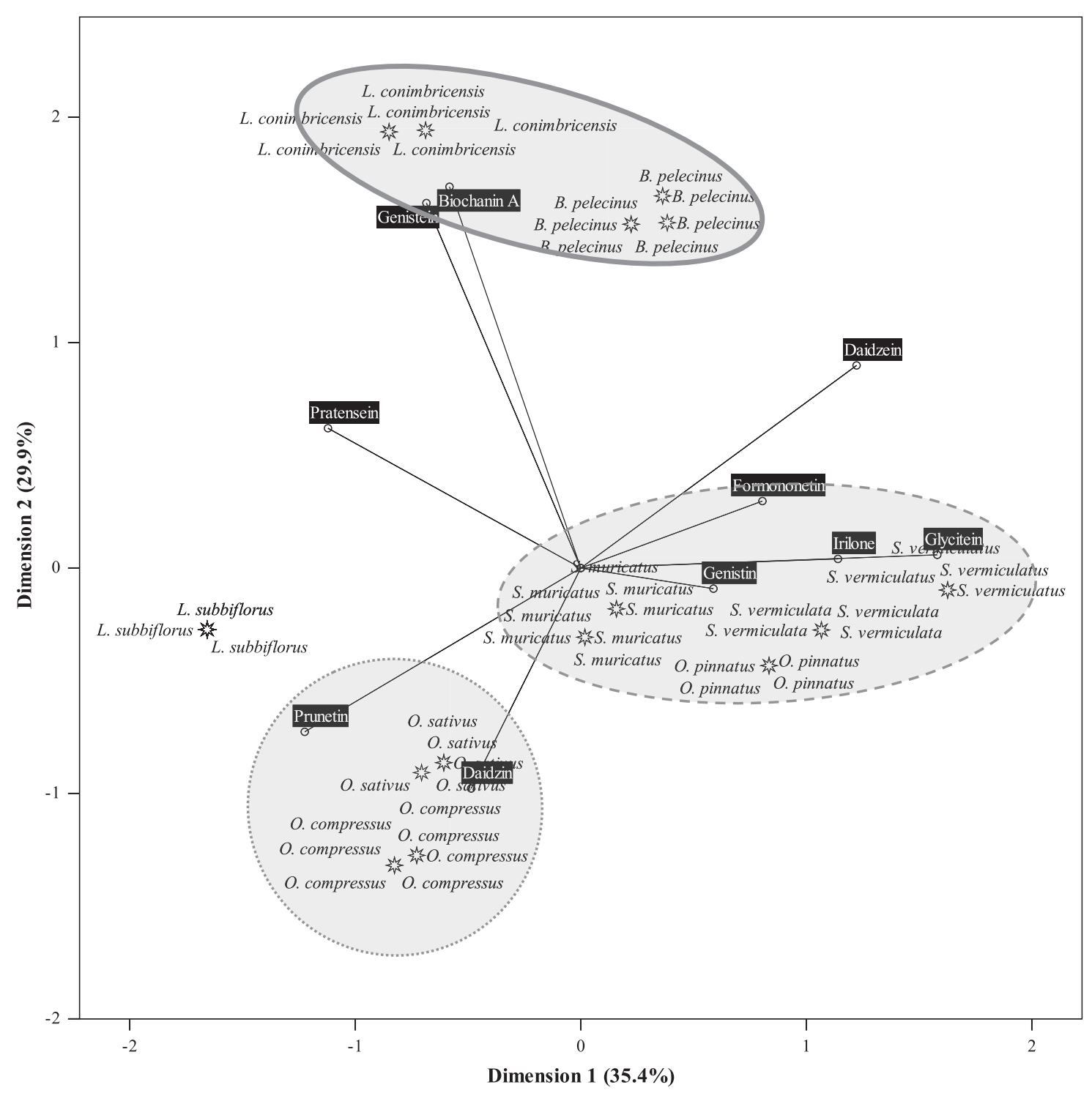

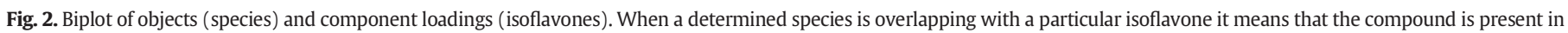
significantly high amounts in that species. 
3.042; second dimension: 2.491 ; third dimension: 1.833 ; fourth dimension: 1.079), the first four dimensions were significant; however, the presented output kept only the first two dimensions in order to allow a more meaningful interpretation. Three main groups were formed (shadowed ellipses): L. subbiflorus was placed far from the remaining species mainly due to its high pratensein and prunetin contents; Ornithopus sativus and 0 . compressus revealed high similarities, mostly due to their high contents in prunetin and daidzein (except for O. sativus) and low levels of daizein; Scorpiurus spp. and O. pinnatus were placed close to each other, but $S$. vermiculata and S. vermiculatus showed the highest similarity, mostly due to their high contents in irilone and glycitein. This spatial distribution of markers enables concluding that isoflavone profile is not exclusively dependent on the plant species. If that was the case, the obtained clusters should correspond to the nine assayed species.

Nevertheless, we hypothesized that the isoflavone profile could be linked to a lower taxonomical rank, opting to verify its association with the genus. To evaluate this hypothesis, a linear discriminant analysis was applied using genus as the grouping factor, simultaneously verifying the differentiation power of the selected variables. The significant independent variables (isoflavones) were selected using the stepwise procedure of the LDA, according to the Wilks' $\lambda$ test. Only those with a statistical significant classification performance $(p<0.050)$ were kept for analysis. In this discriminant model, three functions were defined as being significant (plotted in Fig. 3) integrating 100\% of the observed variance (first: $90.9 \%$; second: $6.2 \%$; third: $2.9 \%$ ), with all variables being selected by the model. Function 1, mainly correlated with pratensein and genistein, as deduced from the canonical discriminant
Table 3

Pooled within-groups correlations between discriminating variables and standardized canonical discriminant functions.

\begin{tabular}{lrrr}
\hline \multirow{2}{*}{ Isoflavone } & \multicolumn{2}{c}{ Discriminant functions } \\
\cline { 2 - 4 } & \multicolumn{1}{c}{2} & \multicolumn{1}{l}{3} \\
\hline Daidzin & -1.234 & 8.512 & 1.926 \\
Genistin & 7.570 & 8.628 & -1.136 \\
Daidzein & -7.663 & -2.729 & 2.872 \\
Glycitein & -6.868 & 8.933 & 5.056 \\
Genistein & 16.370 & 8.123 & -3.311 \\
Pratensein & 20.944 & -9.724 & -0.296 \\
Formononetin & 8.042 & -8.439 & 14.582 \\
Irilone & -11.641 & 2.327 & -15.245 \\
Prunetin & -10.612 & 22.081 & 2.900 \\
Biochanin A & 1.830 & 1.978 & 6.168 \\
\hline
\end{tabular}

functions standardized coefficients (Table 3) separated primarily Lotus and Biserrula from the remaining genera. Function 2, more strongly correlated with prunetin, projected Ornithopus far from any other genus. Finally, function 3, more powerfully correlated with irilone and formononetin, was particularly effective in confirming the separation of Biserrula genus. The complete individualization of the four genera is a strong indicator of the influence of genotypic factors on the isoflavone profiles. In fact, the differences in isoflavone profiles led to a flawless classification performance, allowing classifying correctly $100.0 \%$ of the assayed species for the originally grouped cases as well as for the cross-validated cases. Nevertheless, this specification was not achieved at species level, indicating that other factors besides those ruled by

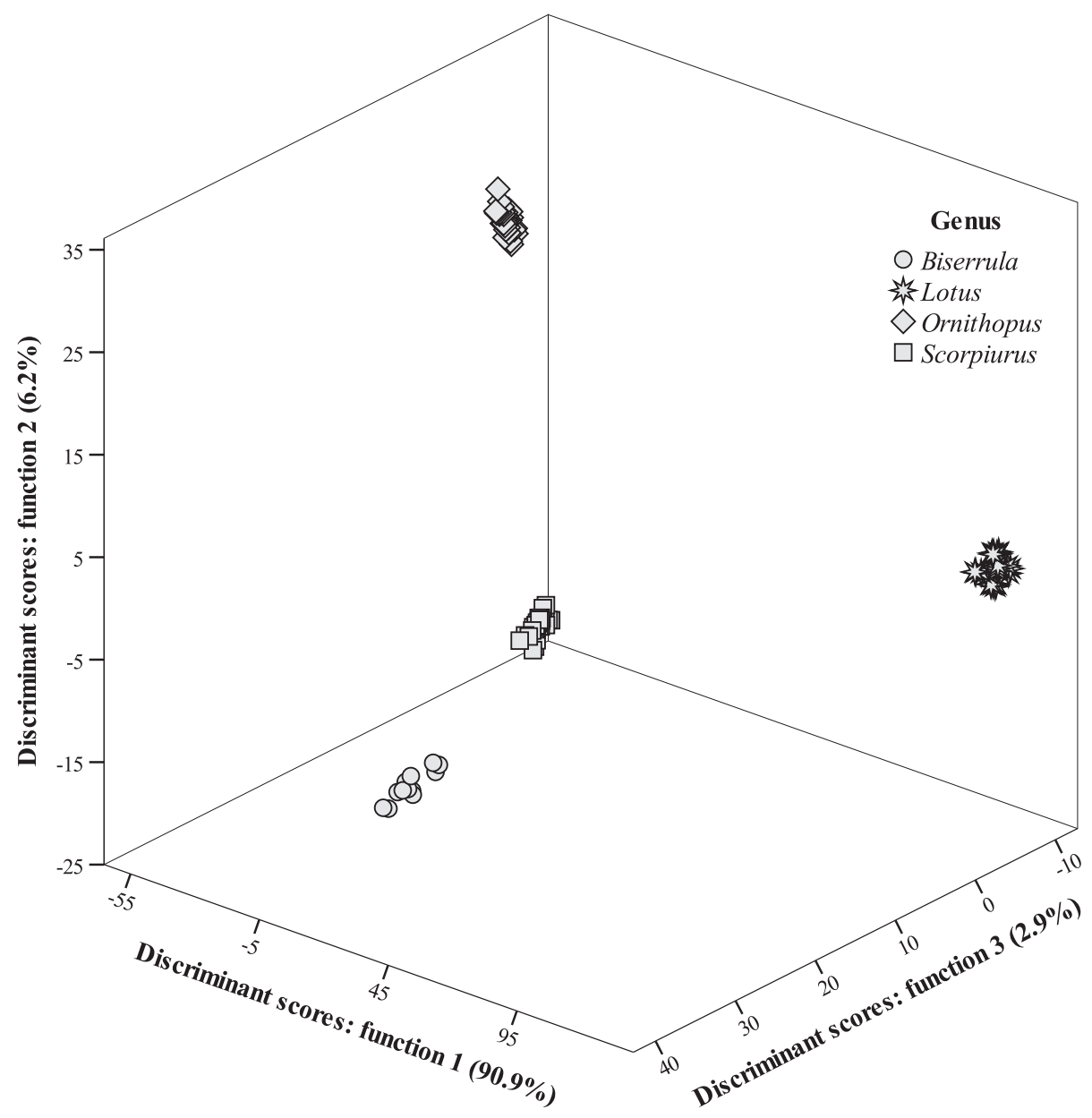

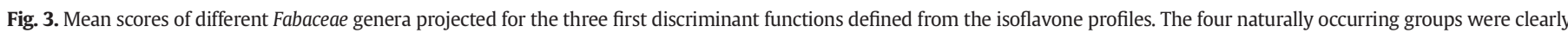
separated. 
genotypic influence play their part in defining the isoflavone production dynamics. Under this approach, several additional factors should be considered. In fact, besides the influence inherent to the genotypic group, the qualitative and quantitative differences, may result from the variation induced by environmental conditions, specifically the stress induced by temperature, light exposure and drought, once that plants faced different temperatures during their vegetative development (the periods of sowing, elongation, transplantation or flowering are not equal among the assayed species) (Bednarek et al., 2003; Sakthivelu et al., 2008). Cultivation year is often indicated as the main source of variation in isoflavones concentration (Hoeck, Fehr, Murphy \& Welke, 2000); however, since all samples were collected in the same year, the detected differences are more likely associated with physiological factors. Low temperatures, for instance, increase the activity of key enzymes of the phenylpropanoid and flavonoid pathways, such as phenylalanine ammonia-lyase and chalcone synthase (Posmyk, Bailly, Szafranska, Janas \& Corbineau, 2005); likewise, low temperatures reduce cell photosynthetic activity, leading to photon flux excess (light stress) responsible for further phenylpropanoid pathway enhancement (Barion et al., 2010).

\section{Conclusion}

The detected profiles indicate a significant association among isoflavones and genus. In fact, the biosynthetic pathway of isoflavones is genetically determined; nevertheless, there are additional factors contributing to the type and concentration of isoflavones present in the assayed species, as indicated by the principal component analysis results. When used as food or feedstuffs, isoflavones might exert beneficial or deleterious effects, depending on their type and concentration. Therefore, knowing the exact isoflavone profile of a natural product is a valuable task. This selective approach might represent an interesting alternative to the metabolic engineering of isoflavonoid biosynthesis in legume and nonlegume crops. Furthermore, the detected isoflavone levels might be indicators of the suitability of the assayed species in what regards the environmental characteristics of their cultivation.

\section{References}

Aguiar, C. L., Baptista, A. S., Alencar, S. M., Haddad, R., \& Eberlin, M. N. (2007). Analysis of isoflavones from leguminous plant extracts by RPHPLC/DAD and electrospray ionization mass spectrometry. International Journal of Food Sciences and Nutrition, 58, $116-124$

Barion, G., Hewidy, M., Mosca, G., \& Vamerali, T. (2010). Intraspecific variability for soybean cotyledon isoflavones in different cropping and soil conditions. European Journal of Agronomy, 33, 63-73.

Bednarek, P., Kerhoas, L, Einhorn, J., Franski, R., Wojtaszek, P., Rybus-Zajac, M., et al. (2003). Profiling of flavonoid conjugates in Lupinus albus and Lupinus angustifolius responding to biotic and abiotic stimuli. Journal of Chemical Ecology, 29, 1127-1142.

Boerma, H. R., John, J. S., \& Molen, J. Y. (2001). U.S. Legume Crops Genomics Workshop. July, 30-31. Maryland: Hunt Valley (White Paper).

Cano, A., García-Pérez, M. A., \& Tarín, J. J. (2010). Isoflavones and cardiovascular disease. Maturitas, 67, 219-226.

Cooper, J. E. (2007). Early interactions between legumes and rhizobia: Disclosing complexity in a molecular dialogue. Journal of Applied Microbiology, 103, 1355-1365.

Doole, G. J., Pannell, D. J., \& Revell, C. K. (2009). Economic contribution of French Seradella (Ornithopus sativus Brot.) pasture to integrated weed management in Western Australian mixed-farming systems: An application of compressed annealing. Australian Journal of Agricultural and Resource Economics, 53, 193-212.

Fiechter, G., Opacak, I., Raba, B., \& Mayer, H. K. (2013). A new ultra-high pressure liquid chromatography method for the determination of total isoflavone aglycones after enzymatic hydrolysis: Application to analyze isoflavone levels in soybean cultivars. Food Research International, 50, 586-592.
Guo, Z. Y., Kong, C. -H., Wang, J. -G., \& Wang, Y. -F. (2011). Rhizosphere isoflavones (daidzein and genistein) levels and their relation to the microbial community structure of mono-cropped soybean soil in field and controlled conditions. Soil Biology and Biochemistry, 43, 2257-2264.

Hackney, B., Dear, B., \& Crocker, G. (2007). Biserrula. Primfact: Profitable \& sustainable primary industries, 632.

Hammerschmidt, R. (2005). Editorial. Phenols and plant-pathogen interactions: The saga continues. Physiological and Molecular Plant Pathology, 66, 77-88.

Hoeck, J. A., Fehr, W. R., Murphy, P. A., \& Welke, G. A. (2000). Influence of genotype and environment on isoflavone contents of soybean. Crop Science, 40, 48-51.

Jacobs, A., Wegewitz, U., Sommerfeld, C., Grossklaus, R., \& Lampen, A. (2009). Efficacy of isoflavones in relieving vasomotor menopausal symptoms - A systematic review. Molecular Nutrition \&' Food Research, 53, 1084-1097.

Khaosaad, T., Krenn, L., Medjakovic, S., Ranner, A., Lössl, A., Nell, M., et al. (2008). Effect of mycorrhization on the isoflavone content and the phytoestrogen activity of red clover. Journal of Plant Physiology, 165, 1161-1167.

Konar, N., Poyrazoğlu, E. S., Köksal, D., \& Artik, N. (2012). Effect of different sample preparation methods on isoflavone, lignan, coumestan and flavonoid contents of various vegetables determined by triple quadrupole LC-MS/MS. Journal of Food Composition and Analysis, 26, 26-35.

Martin, L. M., Castilho, M. C., Silveira, M. I., \& Abreu, J. M. (2006). Liquid chromatographic validation of a quantification method for phytoestrogens, biochanin A, coumestrol, daidzein, formononetin, and genistein in lucerne. Journal of Liquid Chromatography and Related Technologies, 29, 2875-2884.

Mortensen, A., Kulling, S. E., Schwartz, H., Rowland, I., Ruefer, C. E., Rimbach, G., et al. (2009). Review: Analytical and compositional aspects of isoflavones in food and their biological effects. Molecular Nutrition \& Food Research, 53, 266-309.

Mourouti, N., \& Panagiotakos, D. B. (2013). Soy food consumption and breast cancer. Maturitas, 76, 118-122.

Palacios-Morillo, A., Alcázar, Á., Pablos, F., \& Jurado, J. M. (2013). Differentiation of tea varieties using UV-Vis spectra and pattern recognition techniques. Spectrochimica acta, part a: Molecular and biomolecular spectroscopy, 103, 79-83.

Park, C. Y., \& Weaver, C. M. (2012). Vitamin D interactions with soy isoflavones on bone after menopause: A review. Nutrient, 4, 1610-1621.

Patras, A., Brunton, N. P., Downey, G., Rawson, A., Warriner, K., \& Gernigon, G. (2011). Application of principal component and hierarchical cluster analysis to classify fruits and vegetables commonly consumed in Ireland based on in vitro antioxidant activity. Journal of Food Composition and Analysis, 24, 250-256.

Phillips, D. A., \& Kapulnik, Y. (1995). Plant isoflavonoids, pathogens and symbionts. Trends in Microbiology, 3, 58-64.

Posmyk, M. M., Bailly, C., Szafranska, K., Janas, K. M., \& Corbineau, F. (2005). Antioxidant enzymes and isoflavonoids in chilled soybean (Glycine max (L.) Merr.) seedlings. Journal of Plant Physiology, 162, 403-412.

Revell, C., \& Revell, D. (2007). Meeting "duty of care" obligations when developing new pasture species. Field Crops Research, 104, 95-102.

Sakthivelu, G., Devi, M. K. A., Giridar, P., Rajasekaran, T., Ravishankar, G. A., Nikolova, M. T., et al. (2008). Isoflavone composition, phenol content, and antioxidant activity of soybean seeds from India and Bulgaria. Journal of Agricultural and Food Chemistry, 56, 2090-2095.

Santos, A. (2007). A global survey of genus Lotus (Loteae-Fabaceae). Lotus Newsletter, 32, $52-53$.

Saviranta, N. M. M., Veeroos, L., Granlund, L. J., Hassinen, V. H., Kaarniranta, K., \& Karjalainen, R. O. (2011). Plant flavonol quercetin and isoflavone biochanin A differentially induce protection against oxidative stress and inflammation in ARPE-19 cells. Food Research International, 44, 109-113.

Tolleson, W. H., Doerge, D. R., Churchwell, M. I., Marques, M. M., \& Roberts, D. W. (2002). Metabolism of biochanin A and formononetin by human liver microsomes in vitro. Journal of Agricultural and Food Chemistry, 50, 4783-4790.

Udvardi, M., Benedito, V., Zhang, J., Murray, J., Torrez-Jerez, I., Chen, R., et al. (2007). Genomics of Medicago truncatula: Advances and potential use in other species. Lotus Newsletter, 37, 93.

Visnevschi-Necrasov, T., Barreira, J. C. M., Cunha, S. C., Pereira, G., Nunes, E., \& Oliveira, M. B. P. P. (2014). Advances in isoflavone profile characterisation using matrix solidphase dispersion coupled to HPLC/DAD in Medicago species. Phytochemical Analysis, http://dx.doi.org/10.1002/pca.2534.

Visnevschi-Necrasov, T., Cunha, S. C., Nunes, E., \& Oliveira, M. B. P. P. (2009). Optimization of matrix solid-phase dispersion extraction method for the analysis of isoflavones in Trifolium pratense. Journal of Chromatography A, 1216, 3720-3724.

Yildiz, F. (2005). Phytoestrogens in functional foods. Taylor \& Francis Ltd978-1574445084, 210-211.

Yu, O., \& McGonigle, B. (2005). Metabolic engineering of isoflavone biosynthesis. Advances in agronomy. Vol. 86, . Elsevier Inc.

Zielinski, J. (1991). Scorpiurus vermiculatus (Fabaceae) rediscovered in Greece. Willdenowia, 20, 39-41. 